\title{
Las lenguas indígenas entre lo urbano y lo rural: la situación de los pueblos Ette Ennaka, Kankuamo, Arhuaco, Kogui y Wayú 1
}

Pascual Andrés Cossio Romero² Universidad del Magdalena

(iD) https://orcid.org/0000-0003-4304-9050

Resumen: Este artículo, de reporte de caso, busca una reflexión en el plano abstracto y concreto sobre la situación de las lenguas indígenas en el Caribe colombiano. El contexto rural y el urbano han presentado diferentes condiciones para el uso de las lenguas indígenas: en el urbano el trabajo formal e informal ha llevado al uso de otras lenguas, y en el rural la presencia de grupos armados ha imposibilitado, en algunos casos, el uso de estas lenguas como formas de control. Desde estas dos situaciones se trata de mostrar que la política del bilingüismo como forma de superar las brechas económicas, sociales y culturales en el Caribe colombiano no ha sido efectiva y se ha validado el uso del español en algunos pueblos indígenas. De esta manera, el adelanto investigativo que acá se presenta tiene como objetivo analizar la situación del uso de las lenguas indígenas en el contexto rural y urbano de los pueblos ette ennaka, kankuamo, arhuaco, kogui y wayú.

Palabras Clave: Lenguas nativas indígenas, contexto urbano, bilingüismo, Caribe, multilingüe.

Recibido: 15/07/2019| Aceptado: 17/07/2020| Disponible en línea: 30/07/2020

Cómo citar este artículo: Cossio-Romero, P. A. (2019). Las lenguas indígenas entre lo urbano y lo rural: la situación de los pueblos ette ennaka, kankuamo, arhuaco, kogui y wayú. Jangwa Pana 19(2), 331 - 345. Doi: https://doi.org/10.21676/16574923.3609

Abstract: This case report article seeks an abstract and concrete reflection on the situation of indigenous languages in the Colombian Caribbean. The rural and urban context have presented different conditions for the use of indigenous languages, in urban formal and informal work has led to the use of other languages and in rural the presence of armed groups has made it impossible, in some cases, to use of these languages as forms of control. From these two situations, the aim is to show that the policy of bilingualism as a way to overcome the economic, social and cultural gaps in the Colombian Caribbean has not been effective and the use of Spanish in some indigenous peoples has been validated. In this way, the investigative advance presented here aims to analyze the situation of the use of indigenous languages in the rural and urban context of the ette ennaka, kankuamo, arhuaco, kogui, wayú peoples.

Keywords: Native languages, Urban context, Bilingualism, Caribbean, Multilingual.

\footnotetext{
${ }^{1}$ La investigación que acá se presenta no tiene ningún conflicto de intereses en juego.

${ }^{2}$ Correo electrónico: zaratustra0258@gmail.com
} 


\section{Introducción}

Que el 2019 haya sido nombrado el Año Internacional de las Lenguas Indígenas debe llamar la atención de todos los campos de saber humano hacia las poblaciones indígenas y a reconocer la resignificación de sus territorios, sus historias y tradiciones y cómo han debido luchar ferozmente, en el campo simbólico tanto como en el fáctico, para que sus lenguas no desaparezcan (Galindo y Moreno, 2008). De esta manera, el objetivo que plantea este adelanto investigativo es analizar la situación del uso de estas lenguas en el contexto rural y urbano de los pueblos ette ennaka, kankuamo, arhuaco, kogui y wayú.

Es necesario evidenciar que este año reconoce aquellas lenguas que aún se articulan y las que no; dos situaciones que deben ser abordadas desde diferentes saberes (Gamboa, 2007). En la primera es preciso reconocer las dificultades que tienen las lenguas indígenas en la actualidad, su resistencia después de la colonización y lo importante a la hora de conjugar la cosmovisión indígena (Ardila, 2007; Duverger, 1995). En la segunda se requiere reconocer que la pérdida de una lengua deja grandes vacíos dentro de estas comunidades. Se ha visto que cuando se hace uso de una lengua se generan unos procesos singulares de identidad (Garrido, 1993; Larrucea de Tovar y Tovar, 1984; Villegas y Restrepo, 1977), de manera que podría decirse que, dependiendo de la lengua que se hable, así se generarán identidades particulares. Esto queda plasmado en el actuar artesanal de las comunidades indígenas: de tal lengua, tal práctica cultural.

Colombia es un epicentro de encuentros culturales, multiculturales e incluso hiperculturales (Bocarejo, 2011; Rojas y Guzmán, 2007). En efecto, desde la Constitución de 1991 han quedado identificados los diferentes grupos étnicos en Colombia, tanto comunidades indígenas como afro y raizal, y también se pasó a reconocer que los pueblos originarios poseían una lengua viva diferente al castellano antes de la llegada de los españoles (Alarcón, 2007). Es así como no solo se llegó a considerar la tradición histórica de estas poblaciones étnicas en Colombia, sino que se les dio autonomía sobre el uso de su lengua en todo el territorio nacional (Trillos, 2001). De todo esto se han podido impulsar diferentes espacios investigativos, trabajos comunitarios y muestras culturales de una Colombia que habla diferente, de una Colombia multilingüe.

Ahora bien, podría decirse que el Caribe colombiano en particular representa de la mejor forma esta multiculturalidad (Bickerton, 1976; León, 2011) toda vez que es la zona de encuentro entre la cultura africana, la europea, la indígena y el resultado del cruzamiento de estas. Es así como esta región se hace por sí misma polifónica; en otras palabras, multilingüe (Patiño, 2000). Ahora bien, es necesario anotar que aquello que es dicho en diferentes idiomas -en este caso lenguas- se hace más complicado para conocer porque, cuando se cree que se ha capturado el significado total de una palabra, suele aparecer una más compleja de comprender en otra lengua (Winford, 1985, 1997). De ahí podría radicar la dificultad para establecer con precisión todo aquello que es el Caribe.

En el Caribe colombiano se pueden encontrar diferentes lenguas nativas: damana, kogian, ikan, ette taara, tule, yukpa y wayunaiki (Etxebarria, 2012; Trillos, 2018). Cada una es única en su uso, y cada una remite al territorio, a la identidad y a la cosmovisión indígena, pero asimismo cada una debe enfrentar la misma problemática: las dificultades que tienen en todo 
el territorio colombiano, tanto en contextos urbanos como en los rurales. En los primeros, por ejemplo, se ha dado la imposición de otras lenguas para realizar tareas cotidianas (Quintero, 2008), mientras que en los segundos se observa una prohibición de formas de hablar y comunicarse diferentes al español a causa de los grupos armados al margen de la ley, los cuales piensan que el hecho de no entender las lenguas indígenas abre una posibilidad de conspiración contra ellos (Laurent, 2012; Sarrazin, 2009), algo que ha traído como resultado el uso de un español coercitivo.

En este orden de ideas, se hace necesario mencionar que el trato que se les ha dado a las lenguas indígenas no ha sido el mejor: por falta de políticas linguiísticas en todo el territorio colombiano, por el olvido sistemático del Estado a los grupos indígenas y por el ingreso de grupos armados a resguardos donde habitan estos pueblos ancestrales. Como resultado, se han perdido ya varias lenguas en el Caribe colombiano. El caso más llamativo al respecto en la Sierra Nevada de Santa Marta es el del pueblo indígena kankuamo, que además de la lengua (Castro, 2010) perdió algunos aspectos propios de su cultura. De hecho, no es por azar que cuando un pueblo pierde su lengua vaya perdiendo diferentes elementos culturales, pues esta es lo que estructura la vida de una comunidad (Todorov y Burlá,1987). No obstante, esta importancia, lo único que han podido afianzar estos pueblos originarios en su condición étnica han sido su música, religión y territorio, pero no su lengua (Cossio-Romero, 2018).

Una lengua indígena perdida es, a nivel cultural, algo que nunca más podrá escucharse o articularse de nuevo (García-Orellán, 2015). La oralidad de las poblaciones indígenas presenta problemáticas, en términos epistemológicos y metodológicos, mucho más complejos de llevar que los que se dan en torno la escritura. Así, siempre se podrá revisar, revivir y actualizar la lengua que se posa sobre el papel, mientras que la oralidad es algo que supera su misma condición: es etérea, habita en la identidad y las tradiciones indígenas, es algo que al desaparecer no podría revivir los efectos que tiene sobre las tradiciones e historias de estos pueblos ancestrales.

En este orden de ideas, aquellas poblaciones indígenas que resistieron los tiempos de la Colonia, en la actualidad, se están viendo enfrentadas a un desarme cultural fomentado por el capitalismo. Un ejemplo de esto es el contexto urbano, lugar por excelencia de encuentros culturales que valida más unos usos culturales que otros (Santos, 2002), donde la permanencia de algunas poblaciones indígenas representa el desuso de su lengua nativa toda vez que deben ajustarse a la preferencia - o, mejor, la necesidad - de hablar otro idioma en detrimento de su lengua. Se podría entender que el contexto urbano es el predilecto para poner en juego las dinámicas del consumo, y por esta razón les impone a las comunidades indígenas hablar en el idioma de este: un idioma hegemónico (Aubague, 1986) —en el caso colombiano, el español一.

En Colombia se podrían ver dos grandes bloques de políticas lingüísticas, que configuran dinámicas identitarias en todo el territorio colombiano: por un lado, las políticas que buscan regular la correspondencia entre las lenguas no hegemónicas o minoritarias y el español, tema que interesa en este artículo, y por otro lado todo el armazón de las lenguas extranjeras (García y García, 2012). De esta manera se ha buscado regular, en términos ideales, el reemplazo de las lenguas ancestrales por el español en todo el territorio colombiano. No obstante, la realidad es que, en la cotidianidad del consumo, del conflicto armado colombiano 
que aún no termina y de la educación en los pueblos indígenas, se valida el uso del español en detrimento de las lenguas indígenas.

De esta manera, no hay que olvidar los diferentes escenarios que ha dejado el conflicto armado para todos los pueblos colombianos en el contexto rural. Por una parte, el desplazamiento ha llevado a que diferentes grupos se movilicen a las ciudades esperando alejarse de la violencia (Assies, Van der Haar y Hoekema, 2002; Gundermann y González, 2008). Por otra parte, aquellos grupos que se quedan en estos contextos rurales no solo deben soportar la presencia de grupos armados, sino la falta de políticas públicas - y en este caso de políticas lingüísticas-, siendo la del bilingüismo la más naturalizada que llega a sus territorios. Al parecer, en este contexto solo se legisla la tierra, dejando de lado temas tan relevantes como las lenguas indígenas, las tradiciones ancestrales y las ceremonias que por miles de años han configurado la singularidad de todos los pueblos indígenas en todo el territorio colombiano.

Hasta este punto habría que pensar que Colombia se ha transformado en un Estado que valida el uso del español en el contexto urbano y rural, lo cual trae diferentes dificultades a las poblaciones indígenas. Esto queda reflejado en la identidad de los pueblos: así como se hizo en tiempos de la Colonia, cuando se obligó a creer que las lenguas nativas eran malas y pecadoras, ahora se fuerza a pensar que estas lenguas no podrían traer los mismos privilegios que el español u otra lengua hegemónica. Así como la colonización mostró que la mejor forma de acabar con los que resistían era destruyendo su lengua (Chirinos, 1998; RiveraCusicanqui, 1997), hoy este proceso se repite de formas alternas. El bilingüismo, sin embargo, ha tratado de solventar esta situación sopesando la balanza lingüística, aunque en el territorio colombiano sigue siendo un proyecto incipiente que va cobrando forma al ver cómo siguen desapareciendo las lenguas indígenas.

\section{Materiales y métodos}

La presente información se pudo obtener gracias al acercamiento activo de los sujetos que hicieron parte de este adelanto investigativo de corte cualitativo. De esta manera se muestran evidencias de las situaciones que experimentan algunos pueblos indígenas en el Caribe colombiano, pero también se reflexiona desde algunos aspectos propios que presta la lingüística e incluso se aborda el intento de crear unas políticas lingüísticas en el territorio colombiano, tomando en este caso el bilingüismo.

Estos dos elementos -el material obtenido por medio de entrevistas apoyadas por traductores y la reflexión desde conceptos teóricos - serán tomados con el fin de enlazar las realidades sociales con las teorías que buscan dar una explicación a los fenómenos de la sociedad, en este caso la situación de las lenguas indígenas en los territorios rurales y urbanos de los pueblos ette ennaka, kankuamo, arhuaco, kogui y wayú. En todo caso, es necesario tener en cuenta que la información que acá se expone responde a entrevistas obtenidas en contextos muy específicos, reconociendo que en otros lugares del Caribe colombiano la situación de las lenguas indígenas puede ser diferente.

En el marco del estudio de las lenguas indígenas, en esta investigación se hizo uso de una observación y escucha etnográfica (Fleck, 2008; Segura, 2004), en vista de que los elementos 
que se estudiaron van más allá de la observación. Así, aunque esta última puede configurar algunos elementos para estudiar una lengua, en este caso la escucha activa fue la aproximación más adecuada. En este trabajo se hizo uso de un diario de campo que permitió dar cuenta de aquellas situaciones, en el contexto urbano y rural, donde se evidenciaron las diferentes problemáticas que deben afrontar los pueblos indígenas a la hora de hacer uso de su lengua.

Se trabajó con 36 personas pertenecientes a diferentes pueblos indígenas del Caribe colombiano con los que hasta el momento se han podido analizar los dos contextos mencionados: arhuaco, kogui, kankuamo, wayú y ette ennaka. Las entrevistas se llevaron a cabo en espacios de trabajo, contextos de estudio y visitas a casas, buscando tener un acercamiento más estrecho al uso que se le daba a una lengua indígena en un contexto y al español en otros.

Tabla 1. Cantidad de participantes de cada pueblo indígena entrevistado

\begin{tabular}{|l|l|}
\hline Pueblo indígena & Cantidad de participantes \\
\hline Arhuaco & 7 \\
\hline Kogui & 5 \\
\hline Kankuamo & 4 \\
\hline Wayú & 9 \\
\hline Ette Ennaka & 11 \\
\hline Total & 36 \\
\hline
\end{tabular}

Fuente: elaboración propia.

La tabla 2 describe los tres ítems considerados para llevar a cabo la entrevista, que fue semiestructurada. En aquellos casos en los que se presentaban diferentes barreras lingüísticas que no permitían una transcripción al pie de la letra de lo que comentaban los sujetos, se tuvo la ayuda de otros integrantes del pueblo con el fin de hacer más clara la intención de esta investigación.

Tabla 2. Ruta metodológica para superar barreras lingüísticas

\begin{tabular}{|l|l|}
\hline \multicolumn{1}{|c|}{ Ruta metodológica } & \multicolumn{1}{|c|}{ Herramienta } \\
\hline Domina su lengua y habla español & $\begin{array}{l}\text { Entrevista semiestructurada sin } \\
\text { ayuda de traductor }\end{array}$ \\
\hline $\begin{array}{l}\text { Domina significativamente su } \\
\text { lengua y el español }\end{array}$ & $\begin{array}{l}\text { Entrevista guiada por preguntas } \\
\text { puntuales con ayuda de traductor }\end{array}$ \\
\hline $\begin{array}{l}\text { Domina su lengua y no habla } \\
\text { español }\end{array}$ & $\begin{array}{l}\text { Conversación dirigida (Sánchez- } \\
\text { Upegui, 2009) con ayuda total del } \\
\text { traductor }\end{array}$ \\
\hline
\end{tabular}

Fuente: elaboración propia.

\section{Resultados}

A continuación, se presentan diferentes elementos encontrados en las entrevistas realizadas en contraste con la situación que vivían y afrontaban las personas que participaron de este adelanto investigativo. 


\section{Lenguas indígenas y español: ¿hacia un bilingüismo insuficiente?}

Se ha naturalizado en las ciencias sociales que las comunidades indígenas deben abogar por un bilingüismo: hablar no solo la lengua nativa, sino aprender el español. Esto se fomenta en algunos países de América Latina, a excepción de aquellos de habla no hispana, para poder hacer frente al encuentro cultural. No obstante, este mecanismo encierra dentro de sí una preferencia por el uso del español, en algunas situaciones, sobre la lengua nativa, tal como se puede observar en este testimonio:

En mi resguardo, en el colegio, nos enseñaban la lengua, pero solo dos horas a la semana, y era un profesor que no sabía bien la lengua. Las tareas las teníamos que entregar en español, y eso siempre era muy difícil para todos (comunicado personal, Mendinueta, 2019).

Así pues, aunque se profese esta enseñanza del bilingüismo en Colombia, y en el Caribe colombiano, termina siendo una política lingüística fallida que no logra su objetivo, sino que crea valores hegemónicos del español sobre la lengua nativa.

El mejor ejemplo de lo anterior es el contexto urbano, donde las personas, en medio de su trabajo informal, llevan de manera casi automática un consumo cotidiano y muchas prácticas culturales. Esto constituye un caldo de cultivo para darles más valor a sustratos culturales hegemónicos que a otros que no lo son. Así, la ciudad es por excelencia el lugar de homogenización (Saraví, 2008), donde todos deben verse, vestir, consumir y, en este caso, hablar igual que los demás.

En Colombia existen diferentes las causas que han llevado a que las comunidades indígenas se muevan de sus territorios, siempre rurales, a las ciudades. El conflicto armado, el desplazamiento, la no presencia de las entidades del Estado en territorios indígenas y la economía son algunas. Así pues, a la hora de trabajar, practicar sus tradiciones religiosas o incluso comercializar sus producciones artesanales, deben hacerlo en una lengua diferente a la nativa:

Mi mamá se vino para acá para vender mochilas, pero como no sabe hablar del todo el español me tocó venirme a ayudarla. Yo sé muy bien hablar español y le digo lo que la gente quiere que le haga, los tamaños de las mochilas y todo eso. Pero siempre pasa el gringo que no habla español y me dice cosas en inglés que no entiendo. Hay veces que me ayudan los que pasan; otras veces se pierde la venta (comunicado personal, Gómez, 2018).

Como se puede ver, para poder comercializar aquello que representa lo que son las comunidades indígenas, sus mochilas, estas se deben vender en otra lengua que no sea la nativa. El contexto urbano eclipsa entonces los valores tradicionales y hace de ellos una transacción que deja de lado, las más de las veces, una identidad, una cosmovisión y una lengua milenaria. Aquello que se construyó y se estructuró durante miles de años termina en este escenario cuando se obliga al comercio a las comunidades indígenas, un comercio artificial, sea de orden formal o informal. 
Por lo tanto, siempre y cuando el contexto urbano no reconozca la diferencia cultural, identitaria y linguiística, se seguirán perdiendo aspectos culturales que nunca más podrán ser vistos o escuchados en la sociedad humana. Esta situación se presenta ya que las políticas lingüísticas en Colombia se vienen construyendo desde hace pocos años, lo cual permite vislumbrar una realidad que corroe el mundo simbólico ancestral y que debe llevar a la construcción de estas políticas sociales y lingüísticas al servicio de todos los grupos indígenas que venden, comercializan o permutan algunos de los objetos que los identifican.

La situación descrita no solo se da a la hora de comercializar con artesanías propias de poblaciones indígenas, sino también en el campo laboral "formal":

Yo siempre trabajé en las fincas, pero varias veces yo sentía que la gente me tenía miedo y que no me hablaba, siempre me miraban todo raro. Un día me dijeron que no me hablaban porque mis compañeros pensaban que era un brujo porque hablaba todo raro y como siempre viajaba a La Guajira y regresaba me decían que hacía mis trabajitos por ahí. Un tiempo le fue mal a la finca y me dijeron que le hiciera un trabajito cuando yo de eso no sé nada (comunicado personal, López, 2019).

Una de las enseñanzas del estructuralismo es que la única forma de conocimiento es por medio de la diferencia (Lévi-Strauss, 1995). Sin embargo, no solo existe la posibilidad de conocimiento por medio de la diferencia, sino también de la estigmatización, el prejuicio y los juicios de valor sobre aquello que no se conoce. Este es justo el trato que se da a los aspectos culturales que no se conocen en los contextos urbano y rural: el desprecio de unas prácticas culturales por otras, lo cual no permite muchas veces la trashumancia simbólica, sino un estancamiento de esta, de modo que cuando la lengua indígena se estanca (no se habla) puede olvidarse. En ocasiones pareciera que la ciudad, en particular, no puede soportar la existencia de valores diferentes a los hegemónicos, y la forma de deshacerse de estos es borrándolos de la faz cultural, lo cual puede traer consecuencias irreparables sobre el orden cultural.

Así pues, ya que en las ciudades no se hace necesario el uso de las lenguas nativas, sucede algo para las familias de tradición oral que habitan allí. Al ser el español la lengua que usan cotidianamente, lo que se hace es naturalizar el uso de una lengua sobre la otra sin que se adviertan las consecuencias de esta situación, ya que se hace más práctico, a la hora de comercializar un objeto, hablar en una lengua hegemónica que en una ancestral.

Las lenguas indígenas, al ser de tradición oral, deben ser transmitidas de generación en generación, pero ahora se ha incrustado el español a la tradición indígena, de tal forma que aquello que se transmite solo es este último porque es el idioma que permitirá el sustento de las futuras generaciones (Sepúlveda y Zúñiga, 2015). Se ha logrado, incluso, que las comunidades indígenas crean que el uso del español es más importante que la articulación de su lengua nativa (Velasco, 2007).

\section{El porvenir de las lenguas indígenas en el Caribe colombiano}

A la hora de ver las dinámicas de las lenguas indígenas, tanto en el contexto urbano como en el rural, hay que tener en cuenta cuáles son las principales problemáticas que se les presentan 
a estos pueblos para articular su lengua. Son dos contextos que no sirven de pivote para la articulación de las lenguas nativas, sino que son problemáticos para estas. En el primero, que no permite el uso exclusivo de las lenguas nativas, las comunidades indígenas que lo habitan se ven forzadas a dejarlas en desuso. Por otro lado, el segundo, antes por excelencia el territorio de las comunidades indígenas para expresar sus tradiciones, prácticas y conjugar su lengua con el medio (Gerassi, 1995), ahora representa un obstáculo para esto: la presencia de grupos armados al margen de la ley, el olvido sistemático del Estado y la injerencia de una educación fuera de los objetivos de la etnoeducación, por ejemplo, son circunstancias que dificultan que algunas poblaciones indígenas del Caribe puedan hacer uso de sus lenguas nativas de la forma más adecuada. Aunque esta investigación no busca generalizar ya que hay hechos que escapan a estas tres situaciones, estas resultaron recurrentes dentro de las entrevistas realizadas.

Desde el caso del pueblo kankuamo, quienes han tomado las acciones para reforzar sus tradiciones, se espera que las otras poblaciones indígenas de Colombia sigan el ejemplo:

Pues ya no, nosotros no tenemos nuestra lengua. Por eso siempre busco que los grupos nos vean como ejemplo. Aunque tenemos nuestra música y las mochilas, no es lo mismo; hay algo que se perdió en nosotros, en nuestra identidad, en nuestra historia y que nunca va a regresar. Es como cuando un ser querido se le muere a uno (comunicado personal, Villazón, 2018).

En este orden de ideas, el Caribe colombiano ha servido para mostrar los efectos que trae la pérdida de una lengua en la identidad indígena (Mostacero, 2004), lo cual repercute de forma irreparable sobre el tejido cultural.

Ahora bien, se podría pensar que esta problemática ha quedado en un segundo plano por el trato que se les ha dado a las políticas que apuntan a las lenguas indígenas en todo el país, dándoles más preponderancia a los territorios, los cuales, si bien son importantes, no deberían implicar que aquellas dejen de serlo. De ese modo se encuentran muchas políticas en torno al territorio que pertenece a las poblaciones indígenas en Colombia, e incluso cabe observar la relevancia que tomó el campo en los acuerdos de paz entre el Gobierno y las FARC-EP, siempre haciendo mención de esto en relación con los pueblos indígenas, pero nunca hay una indicación clara que apunte a algo respectivo sobre las lenguas de estas comunidades afectadas por el conflicto armando.

Este fenómeno no sugiere de ninguna manera que el conflicto no haya impactado en el uso de las lenguas nativas. Un claro ejemplo es la imposibilidad que tuvo el pueblo ette ennaka para hablar su lengua a causa de que grupos al margen de la ley lo prohibían (Cabildo Indígena Ette Ennaka, 2000). Así, es necesario decir que el trato que se les dé a las lenguas indígenas no puede consistir en acciones secundarias o terciarias, sino primarias. No habría territorio sagrado, en su sentido más extenso, si no hubiera lengua indígena.

De esta manera, la situación del pueblo ette ennaka, tan afectado por la presencia de grupos al margen de la ley, casi lleva a su extinción ya que se llegó a representar a este grupo como campesino y no como indígena en algún momento de su historia. Esto evidencia que la 
presencia de estos grupos al margen de la ley tuvo una injerencia, un funcionamiento y una estructura dentro de varios pueblos indígenas en Colombia:

Yo tengo 24 años y, si usted ve, toda nuestra generación no sabe hablar la lengua. Conoce algunas cositas, por los profesores que le daban unas clases sobre la lengua. Esto no era siempre. Siempre salen las historias de cómo la gente mala mataba a la gente que no se apegaba a las reglas. Si usted ve lo que ha dicho el cabildo, es que nunca se podía hablar la lengua o le podían hacer algo a uno o a la familia. Por eso mismo muchos de nosotros sabemos lo que nos han enseñado nuestros papás y mamás en la casa, pero es muy poco (comunicado personal, Martínez, 2019).

Esta situación validó y naturalizó el uso del español sobre la lengua ette taara en este pueblo indígena, lo cual sigue teniendo unos efectos negativos sobre el conocimiento, uso y articulación de las lenguas nativas. Es por esta razón que se hace necesaria la implementación de políticas lingüísticas que estén al servicio de la identificación, la caracterización y el análisis de los efectos del conflicto armado colombiano en las lenguas ancestrales.

De igual forma, es preciso anotar que existen otros escenarios que validan el uso del español sobre las lenguas indígenas, algo que de seguir ocurriendo podría tener un efecto catastrófico en la cosmovisión de estas comunidades originarias: la cultura se despediría de algo que nunca más podrá ser escuchado, lo cual no pasa muy a menudo. Por ejemplo, incluso el saber universitario las más de las veces valida y naturaliza el español y otras lenguas en el actuar indígena:

Yo desde que estoy en la universidad no me ha sido necesario hablar en mi lengua; solo cuando me encuentro con mis hermanos. Siempre me ponen a leer cosas en español. Un día me mandaron un artículo en inglés. Yo no sabía nada de lo que decía ahí (comunicado personal, Izquierdo, 2019).

Así pues, no es solo la dinámica económica la que valida el uso de una lengua sobre otra, sino también el espacio universitario. Por esta misma razón las acciones que se tomen no solo deben ser a nivel académico, sino que se deben respaldar a nivel de políticas sociales y en la vértebra del fruto social, la labor comunitaria.

Aunque se está iniciando la creación de movimientos indígenas que fortalezcan las lenguas ancestrales, es necesario mostrar que el medio urbano absorbe todo aquello que sea diferente de forma rápida. Por eso mismo, las acciones que se tomen deben ir desde lo rural hasta lo urbano y, muy bien, desde lo urbano hasta lo rural. Ahora, aunque cada uno es un contexto totalmente diferente, trabajando desde estos dos frentes se podrían mejorar, fortalecer y propiciar las acciones que potencialicen el uso de las lenguas nativas en cualquier espacio, reconociendo las dificultades que cada uno presente.

Se piensa que la lengua tiene un fin último. No obstante, la oralidad, con todas sus categorías (Ong y Hartley, 2016) presenta unas particularidades que hasta el momento la escritura no:

Se privilegia entonces el uso de la lengua, concibiéndola como un instrumento de interacción en la resolución de problemas, antes que un objeto de estudio; es decir, se 
traslada la atención de lo que es la lengua a lo que se hace con ella: comunicar (Trillos, 2018, p. 73).

Las lenguas nativas en los pueblos ágrafos presentan nuevas problemáticas a la investigación en el campo de la lingüística, pues antes de comunicar algo deben existir aquellos elementos simbólicos, representacionales y lógicos de una lengua; en otras palabras, debe existir la lengua para que algo se comunique, ya que una forma de comunicación diferente a la lengua nativa cambiará significativamente aquello que se quiera decir. De esta manera, la traducción de aspectos centrales de las dinámicas y tradiciones ancestrales a otra lengua diferente de la que las constituyó no podrá ser suficiente; algo de su esencia se verá perdido.

\section{Discusión}

Las entrevistas realizadas, más la revisión conceptual y teórica del uso de las lenguas indígenas de los pueblos ette ennaka, kankuamo, arhuaco, kogui y wayú, permite vislumbrar cuatro problemáticas en torno a la materia: 1) la presencia de grupos armados al margen de la ley, 2) el olvido sistemático por parte del Estado, 3) las dificultades que se pueden presentar en algunos contextos con la etnoeducación, y 4) la demanda del uso de lenguas hegemónicas para poder comercializar artesanías indígenas. Estas situaciones, y el hecho de que se pueden presentar muchas otras, deben alertar a las futuras investigaciones que se lleven a cabo sobre el tema ya que exigen herramientas, metodologías y formas de recolección de información que tengan en cuenta las particularidades de todos los pueblos indígenas.

Es imperativo que las ciencias sociales enfoquen su mirada en la situación de las lenguas indígenas en vista de que gran parte del contexto colombiano se ha transformado en un espacio que valida el uso del español en detrimento de otras lenguas (Bickerton, 1976; Laurent, 2012; León, 2011; Sarrazin, 2009). El bilingüismo que se ha presentado como el ideal de la educación de los pueblos indígenas no está siendo suficiente a la hora de afrontar y reconocer la importancia de las lenguas nativas en la construcción de una cosmovisión indígena (Cossio-Romero, 2018; García-Orellán, 2015; Winford, 1985, 1997), lo cual se evidencia en el desuso y en una identidad frágil en varios pueblos indígenas del Caribe colombiano.

La investigación de las lenguas indígenas debe dar luces sobre la situación que afrontan las personas que hablan un idioma diferente al español, en este caso los pueblos indígenas. Es preciso considerar que el contexto urbano se presenta como un espacio homogeneizador, lo cual trae como resultado la imposición de una lengua hegemónica sobre otra, en este caso el español por encima de las lenguas indígenas del Caribe colombiano (Assies et al., 2002; Saraví, 2008). A su vez, el trabajo informal, la falta de políticas públicas y linguísticas, y una educación basada en elementos ajenos al contexto (Sepúlveda y Zúñiga, 2015) han llevado a que se valide el uso de prácticas culturales sobre otras, lo cual debe repensarse en un contexto multilingüe.

Por otro lado, el contexto rural, el que anteriormente se pensaba indígena (Gundermann y González, 2008), ha pasado a ser un lugar de prohibición para estos pueblos toda vez que los grupos armados al margen de la ley presentes en él han restringido el uso de cualquier lengua, dialecto o forma de comunicación que no sea el español. De este modo se ha validado y 
consolidado un español coercitivo, así como sucedía en tiempos de la Colonia (Garrido, 1993; Larrucea de Tovar y Tovar, 1984; Villegas, y Restrepo, 1977). La investigación, entonces, también debe considerar estos espacios rurales y romper las barreras de la observación para plantearse un trabajo activo de escucha con miras a reconocer las problemáticas que estos pueblos tienen.

Asimismo, en el contexto rural se requiere abordar el olvido sistemático del Estado, que cada día invisibiliza la situación de todos los pueblos que son minoría en Colombia. Muy seguramente, si se desconoce la situación de un pueblo, se desconocerá la importancia de la lengua que este pueda tener. El hecho de que el Estado colombiano y algunos países de América Latina hayan logrado pensar que el único idioma que se habla es el español (Todorov y Burlá, 1987) ha dificultado particularmente la existencia misma de las lenguas diferentes, ya que se relacionan con prácticas ajenas como la brujería o incluso con la conspiración.

En el contexto colombiano no solo hacen falta políticas públicas y lingüísticas que piensen y puedan mejorar la situación de las lenguas indígenas en todo el territorio nacional, sino que se requiere investigar en estos temas. No hay política con responsabilidad social sin un marco investigativo (Fleck, 2008; Laurent, 2012; Sarrazin, 2009; Segura, 2004). Por esta razón, el reconocimiento de un año internacional de las lenguas indígenas debe motivar y mover el andamiaje académico, sobre todo considerando que la lengua indígena tiene la particularidad de ser de tradición oral, lo cual significa que puede desaparecer en cualquier momento. A falta de teorías, conceptos y metodologías, está la riqueza multilingüe que presta todo el territorio colombiano, que espera ser escuchado e investigado por las ciencias en general. De este modo, a la academia le queda el gran reto de reivindicarse en muchos aspectos con los pueblos indígenas, algo que poco a poco se ha venido haciendo.

Uno de los temas a los que se les apuesta en la academia es pensar el territorio indígena que se ha perdido, vendido o negociado por causa del conflicto armado colombiano o bien el desplazamiento enmascarado en una búsqueda de una mejor vida en las grandes ciudades (Velasco, 2007). No obstante, este enfoque ha dejado de lado la importancia que tiene la lengua en la constitución, no de una geografía, sino de un territorio, ya que este se construye y se significa a partir, precisamente, de su lengua materna, de su lengua indígena. Así pues, se podría decir que sin lengua no hay territorio, o que este último podría hacerse problemático a la hora de vivirlo (Ardila, 2007; Duverger,1995).

En este orden de ideas, es necesario darles la debida importancia a las lenguas indígenas a la hora de configurar la cosmovisión ancestral en diferentes contextos (Bocarejo, 2011; Rojas y Guzmán, 2007). Si bien es claro que el contexto rural resignifica cualquier orden simbólico, esto no debe implicar una desaparición, tal como está sucediendo con la imposición del español sobre la población que llega al contexto urbano. Es necesario entonces repensar todas las políticas sobre la materia y evidenciar el rol primordial de las lenguas indígenas a la hora de analizar, pensar o investigar aquello que se denomina territorio, ya que cada pueblo indígena ha construido su territorio, sus prácticas ancestrales y sus rituales de formas alternas por la misma diferencia en sus lenguas. Así, en últimas, la pérdida de esta diversidad traerá consigo un sinfín de detrimentos a estos pueblos, así como el Caribe lo ha evidenciado con los pueblos que hasta el momento han perdido sus lenguas nativas. 


\section{Conclusiones}

Siendo el Caribe un espacio geográfico rico en elementos multiculturales y multilingües, se hace necesario ver el panorama de las lenguas nativas, no solo en el contexto urbano sino, muy bien, en el rural. Los dos son espacios que se han configurado desde el tiempo de la Colonia como homogeneizadores, con diferencias en cada escenario y momento histórico. Así, mientras que en las ciudades se privilegia la articulación de lenguas hegemónicas, en el campo la intimidación de grupos armados al margen de la ley durante años ha restringido el habla en una lengua diferente al español.

Se requiere buscar espacios de construcción de investigaciones con los pueblos indígenas, con el fin de aportar una forma de identificación de las principales problemáticas que han llevado a que las lenguas de estas comunidades en el Caribe colombiano se vengan silenciando poco a poco. Con este fin se debería incluir a los sujetos que hagan parte de los diferentes pueblos originarios que habiten en los contextos urbano y rural, de manera que se puedan contrastar visiones y puntos de vista. Asimismo, es imperativo consolidar políticas lingüísticas urgentes o robustecer aquellas que están puestas sobre leyes y decretos por parte del Estado con miras a reforzar y salvaguardar el uso de las lenguas indígenas en todos los contextos, tanto a la hora de comercializar un objeto como a la de estar con las personas más cercanas. Es de vital importancia iniciar estos procesos antes de que más lenguas indígenas se pierdan.

El trabajo formal e informal en las ciudades, que se llaman multiculturales, no tiene las políticas linguísticas suficientes para que los pueblos indígenas puedan comercializar sus artesanías (Weiss, Engelman y Valverde, 2013) o bien trabajar de manera formal sin que se afecte la articulación de su lengua. El panorama colombiano no se muestra como el más adecuado para impulsar espacios de encuentros culturales entre unos pueblos y otros. De hecho, en ocasiones pareciera que la hibridación no existe en términos lingüísticos, ya que siempre será rebasada una lengua indígena de tradición oral por una hegemónica de tradición escrita.

Es alarmante lo que ha sucedido con las lenguas indígenas, no solo en el Caribe colombiano, sino en toda Colombia y también en todo el mundo (Beauclair, 2013). Por ello es necesario reconocer que no hay garantías suficientes para que se pueda preservar el uso de las lenguas nativas en el contexto colombiano. Algunas acciones que se han venido tomando son todas aquellas relacionadas con el retorno a los territorios que han sido quitados a las comunidades indígenas desde los tiempos de la Colonia, lo que hoy es una lucha continua. Sin embargo, este esfuerzo no debe ser solo sobre el territorio. Aunque este último es un aspecto muy importante en la cosmovisión indígena, es necesario plantear la siguiente pregunta: ¿cómo podrían los pueblos indígenas nombrar aquello que es sagrado si faltan las palabras? Se podría decir que, por medio del español, pero no es lo mismo; cada lengua, cada idioma, cada acto comunicativo del sujeto significa y resignifica las cosas de modos alternos, lo cual se ve expresado en la cultura que profesa cada pueblo en la humanidad.

En definitiva, se destacan cuatro aspectos para tener en cuenta a la hora de consolidar una investigación que busque ahondar en dinámicas lingüísticas. El primero es la presencia e injerencia de los grupos armados al margen de la ley sobre territorios indígenas, que puede 
traducirse, como en el caso del pueblo ette ennaka, en prohibición de las lenguas ancestrales. El segundo son los efectos que ha traído sobre las dinámicas indígenas el olvido sistemático por parte del Estado, ya que muchos entes gubernamentales no han logrado capturar la realidad de las lenguas indígenas en todo el territorio colombiano. En tercer lugar, está la etnoeducación, la cual, pese a haber sido configurada con los ideales de reforzar las tradiciones de los pueblos indígenas, en la realidad no brinda las herramientas y los espacios suficientes para llevar a cabo esta ardua tarea. Por último, se destaca cómo el consumo ha validado el uso de lenguas hegemónicas para permitir un comercio de un objeto, por más que este esconda detrás de sí una historia de miles de años.

\section{Agradecimientos}

Agradezco a todas las personas que me brindaron un espacio en su trabajo, sus estudios y su vida cotidiana ya que en ustedes pude conocer un mundo diferente, hablado en otras lenguas, con palabras muchas veces imposibles de traducir al español. De igual forma, más que un agradecimiento por el apoyo en esta investigación, mi agradecimiento para ustedes es que mantienen vivos muchos mundos posibles ya que han resistido a diferentes tiempos, épocas y situaciones y aun así siguen haciéndole frente a todo lo que se les presenta. Gracias a ustedes hoy se puede seguir hablando - y se seguirá hablando- de un Caribe y un territorio colombiano multilingüe.

\section{Referencias}

Alarcón, D. (2007). Bilinguismo indígena en Colombia. Gist: Education and Learning Research Journal, (1), 24-38.

Ardila, O. (2007). Estudio sociolingüístico del Amazonas. Revista internacional Magisterio, $25,48-51$.

Assies, W., Van der Haar, G. y Hoekema, A. J. (2002). Los pueblos indígenas y la reforma del Estado en América Latina. Papeles de Población, 8(31), 95-115.

Aubague, L. (1986). Les stratégies de résistance des langues précolombiennes au Mexique. Langages, (83), 111-116.

Beauclair, N. (2013). Oralidad y escritura: consideraciones teóricas sobre la consignación del conocimiento indígena. Tinkuy: Boletín de Investigación y Debate, (20), 101-109.

Bickerton, D. (1976). Pidgin And Creole Studies. Annual Review of Anthropology, 5, 169193.

Bocarejo, D. (2011). Dos paradojas del multiculturalismo colombiano: la espacialización de la diferencia indígena y su aislamiento político. Revista Colombiana de Antropología, 47(2), 97-121.

Cabildo Indígena Ette Ennaka (2000). Plan de Vida Ette Ennaka. Organización del Pueblo Ette Ennaka. Issa Oristunna.

Castro, C. M. (2010). La educación indígena ika, kankuama, nasa, wayúu y mokaná fortalecen la interculturalidad en Colombia. Educación y Humanismo, 12(19), p. 1734.

Chirinos, A. (1998). Las lenguas indígenas peruanas más allá del 2000. Revista Andina, 32, 453-480.

Cossio-Romero, P. A. (2018). El pueblo kamkuamo: en búsqueda de una identidad perdida. Oraloteca, (9), 24-35. 
Duverger, J. (1995). Repères et enjeux. Revue Internationale d’Éducation. Enseignements Bilingues, 7, 29-44.

Etxebarria, M. (2012). Bilingüismo y realidad sociolingüística de la lengua del grupo Wayuu en el Caribe Colombiano. Anuario del Seminario de Filología Vasca" Julio de Urquijo", 46(2), 271-293.

Fleck, D. W. (2008). Sugerencias metodológicas para realizar trabajo de campo lingüístico en la Amazonía. Lexis, 32(2), 251-280.

Galindo, A. y Moreno, L. M. (2008). Estructura, resultados y retos del programa de bilingüismo colombiano 2004-2019. Revista de Investigaciones de la Universidad del Quindio, 18, 172-179.

Gamboa, J. C. (2007). Colombia: Una enriquecedora torre de babel. Revista Internacional Magisterio, 25, 24-27.

García, J., \& García, D. (2012). Políticas lingüísticas en Colombia: tensiones entre políticas para lenguas mayoritarias y lenguas minoritarias. Boletín de filología, 47(2), 47-70.

García-Orellán, R. (2015). Retos metodológicos: de la oralidad al texto. Antropológicas, 13, 57-66.

Garrido, M. (1993). Reclamos y representaciones: Variaciones sobre la política en el Nuevo Reino de Granada, 1770-1815. Bogotá: Banco de La República.

Gerassi, N. (1995). Huarochirí: Recordando las voces del pasado en los mitos de creación. Revista Iberoamericana, 61(170), 95-105.

Gundermann, H. y González, H. (2008). Pautas de integración regional, migración, movilidad y redes sociales en los pueblos indígenas de Chile. Universum (Talca), 23(1), 82-115.

Larrucea de Tovar, C. y Tovar, A. (1984). Catálogo de las lenguas de América del Sur. Madrid: Gredos.

Laurent, V. (2012). Cultures en conflit (s)? Peuples indigènes et politiques publiques en Colombie, vingt ans de réflexions. Cahiers des Amériques Latines, (71), 75-94.

León, D. L. G. (2011). Las lenguas criollas del Caribe: Orígenes y situación sociolingüística, una aproximación. Forma y Función, 24(2), 41-67.

Lévi-Strauss, C. (1995). Antropología estructural. Buenos Aires: Ediciones Paidos.

Mostacero, R. (2004). Oralidad, escritura y escrituralidad. Sapiens. Revista Universitaria de Investigación, 5(1), 53-75.

Ong, W. J. y Hartley, J. (2016). Oralidad y escritura: tecnologías de la palabra. Fondo de Cultura Económica.

Patiño, C. (2000). Sobre etnolingüística y otros temas. Bogotá: Instituto Caro y Cuervo.

Quintero, R. M. (2008). Las organizaciones indígenas y campesinas frente al conflicto armado en el norte del Cauca. Sociedad y Economía, (15), 145-167.

Rivera-Cusicanqui, S. (1997). La noción de "derecho" o las paradojas de la modernidad postcolonial: indígenas y mujeres en Bolivia. Temas Sociales, (19), 27-52.

Rojas, A. y Guzmán, E. C. (2007). Multiculturalismo y políticas educativas ¿interculturalizar la educación? Revista Educación y pedagogía, 19(48), 11-24.

Sánchez-Upegui, A. A. (2009). Nuevos modos de interacción educativa: análisis lingüístico de un foro virtual. Educación y Educadores, 12(2), 60-75.

Santos, B. D. S. (2002). Hacia una concepción multicultural de los derechos humanos. El Otro Derecho, (28), 59-83.

Saraví, G. A. (2008). Mundos aislados: segregación urbana y desigualdad en la ciudad de México. Eure (Santiago), 34(103), 93-110. 
Sarrazin, J. P. (2009). Le rôle des élites intellectuelles dans le processus de visibilisation des indigènes en Colombie. E-Migrinter, 4, 100-106.

Segura, S. G. (2004). De la educación indígena a la educación bilingüe intercultural. La comunidad purhepecha, Michoacán, México. Revista Mexicana de Investigación Educativa, 9(20), 61-81.

Sepúlveda, B. y Zúñiga, P. (2015). Geografías indígenas urbanas: el caso mapuche en La Pintana, Santiago de Chile. Revista de Geografía Norte Grande, (62), 127-149.

Trillos, M. (2001). Por una educación para la diversidad. Nómadas (Col), (15), 162-177.

Trillos, M. (2018). Español-L2 en el contexto multicultural y plurilingüe de la región caribe. Lingüística y Literatura, (73), 72-95.

Todorov, T. y Burlá, F. B. (1987). La conquista de América: el problema del otro. México D.F.: Siglo XXI.

Velasco, L. (2007). Migraciones indígenas a las ciudades de México y Tijuana. Papeles de Población, 13(52), 183-209.

Villegas, J. y Restrepo, A. (1977). Resguardos Indígenas, 1820- 1890. Medellín: Universidad de Antioquia.

Weiss, M. L., Engelman, J. y Valverde, S. (2013). Pueblos indígenas urbanos en Argentina: un estado de la cuestión. Pilquen-Sección Ciencias Sociales, 16(1), 4-14.

Winford, D. (1985). The Concept of "Diglossia" in Caribbean Creole. Situations Language in Society, 14(3), 345-356.

Winford, D. (1997). Re-examining Caribbean English Creole continua. World Englishes, 16(2), 233-279. 